\title{
THE CHARACTERISTICS AND TECHNICAL FOUNDATIONS OF MOBILE COMMERCE
}

\author{
Ruidong Zhang, University of Wisconsin-Eau Claire, zhangr@uwec.edu \\ Tom Hilton, University of Wisconsin-Eau Claire, hiltonts@uwec.edu
}

\begin{abstract}
The traditional e-commerce is generally restricted to a fixed environment with a desktop-based computer. As smartphones and other mobile devices become pervasive and affordable, mobile commerce (or m-commerce) has taken off. M-commerce can be conducted anywhere and anytime on a mobile platform, and can be location aware. It has opened a new door to the next generation of e-commerce. What are the technical foundations of $m$-commerce? What are the major characteristics of m-commerce? These are the major research questions for this study. The uniqueness of m-commerce compared to traditional e-commerce, the unique marketing context, the technical foundation, and the m-commerce consumers' general characteristics are addressed in this paper. All of these will help identify major issues facing m-commerce and can lead to future advanced studies on m-commerce.
\end{abstract}

Keywords: M-commerce, Information privacy, E-commerce.

\section{INTRODUCTION}

M-commerce refers to a consumer's capability to buy or sell a product or service on the Internet via a mobile device, such as a smart phone or a tablet. As smartphones and other mobile devices become pervasive and affordable as well as mobile Internet becomes more ubiquitous, m-commerce has taken off. In the United States, m-commerce sales were predicted to grow $100 \%$ in 2010 to $\$ 2.4$ billion from $\$ 1.2$ billion in 2009 , which represents a $203 \%$ jump from $\$ 396$ million in 2008 [1]. By 2015, ABI predicts that shoppers worldwide will spend \$119 billion on goods and services purchased via mobile phones; however, this still represents only about $8 \%$ of total e-commerce sales, indicating a great potential for m-commerce growth.

According to IBM's online retail benchmark study [5], on Cyber Monday 2011, 10.75\% of people among all online users, used a mobile device to visit a retailer's site, up from 3.88\% in 2010; and on Black Friday 2011, $14.33 \%$ of people among all online users, used a mobile device to visit a retailer's site, up from 5.56\% in 2010. Mobile sales grew dramatically, reaching $6.58 \%$ of the total online sales on Cyber Monday 2011 versus 2.25\% in 2010; and reaching $9.84 \%$ on Black Friday 2011 versus 3.18\% in 2010. Comparing Black Friday with Cyber Monday 2011, Black Friday generated more mobile data traffic (14.3\% vs. $10.8 \%)$, and more mobile sales $(9.8 \%$ vs. $6.6 \%)$. In addition, Android-based smart phones and iPhones are the most popular mobile devices for m-commerce.

Compared with the traditional desktop based e-commerce, m-commerce has offered non-comparable advantages: anytime, anywhere, more personal, more location aware, more context-aware, more age aware, always online and instant connectivity. M-commerce has opened a new era of e-commerce and behavioral marketing. In this study we focus on smart phones or mobile phones with Internet capabilities that can be used by a consumer to conduct anytime and anywhere e-commerce activities. For the purpose of convenience, we call the smartphones and the mobile phones that have Internet capabilities altogether smartphones; and we call the smartphone and the mobile phone users as mobile users or mobile consumers. 


\section{Issues in Information Systems}

Volume 13, Issue 2, pp. 394-396, 2012

THE TECHNICAL FOUNDATION FOR M-COMMERCE

Thanks to the convergence of modern Internet and mobile phone technologies, wireless data communications has become an enabler for powerful and convenient computing on a mobile device platform. A mobile phone with proper processing capability is no longer just a voice device. It has become a smart phone - a data communication device. A smartphone with data capabilities enables a user to have the $24 \times 7$ mobile Internet access in his pocket.

However, for m-commerce to take off, several other conditions need to be satisfied. First, the mobile phones must have the Internet or data capabilities. The traditional web site design must be modified to allow data to fit into the smaller smart phone screen, or, alternatively, smartphone Apps (similar to iPhone Apps) need to be developed to enable consumers to conveniently access m-commerce sites. Fortunately, new innovations such as Web 2.0 are enabling changes in traditional marketing and e-commerce. Web 2.0 is a business revolution driven by the use of the Web as a platform for innovation. It is redefining the new rules for value creation on the web platforms. Facebook and Google+ are examples of Web 2.0 companies that are transforming themselves into m-commerce enablers. A recent study has shown that by adopting five critical success factors: innovation ability, connectivity, complementarities, efficiency, and network effects, Web 2.0 companies become platform leaders [7].

Second, the mobile data network infrastructure needs to be powerful and is pervasive. This means that cellular networks have upgraded to at least to $2.5 \mathrm{G}$, preferably to $3 \mathrm{G}$, so that the mobile phones can access the graphic-intensive m-commerce web site rapidly regardless of whether a Wi-Fi hotspot is available or not. For $\mathrm{m}$-commerce, the availability of a Wi-Fi spot is a just supplement, but should not be a constraint to smart phones.

Over the last several years, significant improvements have been done in above two areas. More importantly, the convergence of information technology along multiple dimensions has allowed the eco-system for m-commerce to grow more mature. There are four general convergence trends that have been identified to be significant to the formation of the eco-system for m-commerce [6]. These four trends are network convergence, industry convergence, technology convergence, and trust convergence. The trust convergence among the four convergence trends is especially important to m-commerce in that mobile trust may be more challenging to establish than traditional e-commerce.

Third, the number of smart phone users needs to reach a critical mass for the m-commerce to grow in scale quickly and significantly. Thanks to high-cost model subsidies (e.g. iPhones) and low cost Android-based models (e.g. some HTC and Samsung models), smart phones sale are increasing quickly. According to Gartner [3], worldwide mobile phone sales to consumers totaled 1.6 billion units in 2010, a 31.8 percent increase from 2009; and the smart phone sales to consumers were up $72.1 \%$ from 2009 and accounted for $19 \%$ of total mobile phone sales in 2010 . On US mobile phone market, Nielsen reported that $31 \%$ of US mobile phone owners have a smartphone as of December 2010 (Nielsen, 2011). It was predicted that the number of mobile devices accessing the Internet worldwide will surpass 1 billion by 2013, and the number of smart phone users worldwide would likely reach more than 900 million by the end of 2013 [4].

\section{THE CHARACTERISTICS OF M-COMMERCE}

There are 3 unique marketing contexts that have been identified: the traditional brick and mortar marketing context, the cyber marketing context which can be broken down into two contexts: the traditional e-commerce online marketing context, and the emerging m-commerce marketing context.

M-commerce is unique because of the unique m-commerce marketing context created. The consumer identity can be revealed more instantly and easily compared with traditional online e-commerce. Your mobile number is your identity and your mobile phone is always connected and can be tracked. Some researchers argued that the mobile Internet promises at least the possibility of the disruption of privacy not only at home, but everywhere, and they even went further to call $\mathrm{m}$-commerce the end of the anonymous consumers [8]. 


\section{Issues in Information Systems}

Volume 13, Issue 2, pp. 394-396, 2012

The ubiquitous feature of the mobile Internet means m-commerce can be conducted anywhere and at any time. This has created opportunities for marketers to push mobile ad and text messages or mobile coupons to a smartphone with a potential of violating a smartphone owner's privacy and information confidentiality requirements. This has created unique challenges to $\mathrm{m}$-commerce. The challenge is from any marketers looking to capitalize on m-commerce [8]. This could have impacts over consumer's behavior in conducting m-commerce.

M-commerce also could face a less secure security environment. Mobile devices send and receive data through open air space where anyone with the right technology can intercept it. Although encryption technologies are available, they are not always properly configured by the wireless network providers or owners. Based on a survey [2], 52\% of the mobile users were concerned about credit card security, which prevented them from becoming m-commerce consumers.

\section{THE ISSUES FACING M-COMMERCE}

The unique characteristics, together with the technical foundations, are creating unique challenges to m-commerce. Among them, the prominent one is the mobile user's increasing privacy and security concerns. Not taking this seriously could slow down the growth of m-commerce. This will lead to a future study on m-consumer's concerns over privacy issues. The benefits of studying mobile consumers' concerns over m-commerce have at least 3 aspects: 1) It can help raise the awareness of marketers or vendors to protect customer privacy data; 2) It can raise consumer's awareness on m-commerce privacy concerns; and 3) It can help marketers or vendors understand meaningful ways to establish good customer relationships using privacy profiling study results as presented in this study.

\section{CONCLUSIONS AND FUTURE RESEARCH}

In this paper, the m-commerce uniqueness and its unique marketing context as well as its technical foundation are addressed. These unique attributes of $\mathrm{m}$-commerce have created more unique issues facing $\mathrm{m}$-commerce. Among these issues, the consumers' concerns over privacy have become a major issue that can affect their intentions of engaging in m-commerce transactions. Therefore, this paper presents a first step that can lead to a more advanced study on m-commerce consumers' privacy concerns. Future research on m-commerce should make it a top priority to identify the major factors that affect mobile consumer's privacy concerns over m-commerce, such as location-based digital couponing and context-aware advertisement, and whether consumers can accept the concept of selling privacy as a commodity.

\section{REFERENCES}

1. Deatsch, Katie, "U.S. m-commerce sales to hit \$2.4 billion this year, ABI Research says," Internet Retailer, February 16, 2010, available at http://www.internetretailer.com/2010/02/16/u-s-m-commerce-sales-to-hit-2-4-billion-this-year-abi-researc.

2. Forrester Research (2010), “Global m-commerce standard in development", http://www.nua.ie/ surveys/index.c-gi?f=VS\&art_id=905355736\&rel=true, accessed on April 192011.

3. Gartner, Press Release on February 9, 2011, http://www.gartner.com/it/page.jsp?id=1543014, accessed on February 13, 2012.

4. Gonsalves, Antone, "1 Billion Mobile Internet Devices Seen By 2013," InformationWeek, December 09, 2009.

5. IBM Core Metrics Benchmark, "Cyber Monday Report 2011," available at http://www.coremetrics.com/solutions/benchmark-report-black-friday-cyber-monday-2011.php, 2011.

6. Lee, Sang M., S. Park, S. Yoon and T. Hwang, "Ubiquitous computing and its effects on small businesses," Service Business Journal, Volume 2, Number 4, 2008, Pages 347-358.

7. Lee, Sang M., T. Kim, Y. Noh and B. Lee, "Success factors of platform leadership in web 2.0 service business," Service Business Journal, Volume 4, Number 2, 2010, Pages 89-103.

8. Milne, George R. and Andrew J. Rohm (2003), "The 411 on Mobile Privacy," Marketing Management, July/August 2003, Page 41-45. 